\title{
HOW DO RETINOBLASTOMA TUMOURS FORM?
}

\author{
BRENDA L. GALLIE* $\S \dagger$, JAMES M. DUNN $\S *$, PAUL A. HAMEL $\S \S$ MICHELLE MUNCASTER $\dagger \S$, \\ BRENDA L. COHEN $\S$, and ROBERT A. PHILLIPS, $† \S$
}

Toronto, Canada

\begin{abstract}
SUMMARY
The causes of retinoblastoma $(R B)$ can now be described with considerable accuracy, although many details are still unclear. Understanding the genetic changes leading to $\mathbf{R B}$ has provided an awareness of general mechanisms of cancer development and progression, previously only suspected. From the basic understanding have come new diagnostic technologies that are now ready to be applied directly to $\mathbf{R B}$ patients and their families, and a rational approach, based on this understanding, will help us to develop new therapies that avoid the severe complications of conventional treatment.
\end{abstract}

\section{MUTATIONS OF THE RBI GENE INITIATE RB TUMOURS}

The $R B 1$ gene was identified because mutations in both alleles result in $\mathrm{RB} .^{1,2}$ All children with bilateral $\mathrm{RB}$ have a germline mutation in $R B I$ and develop tumours when the second, normal allele is lost or mutated. The non-heritable RB tumours arise when both alleles are mutated in one retinoblast in an individual with normal $R B I$ alleles; these events are each so rare, that the tumour is always unifocal and unilateral. However, $15 \%$ of the unilaterally affected patients do have a germline $R B I$ mutation.

Although bilaterally affected patients may inherit a defective $R B I$ gene, most have no family history of $\mathrm{RB}$ and have new germline mutations, proven in some cases. ${ }^{3,4,5}$ In these patients, the answer to the title question begins when poorly-defined factors cause that initial germline mutation. Cytogenetic ${ }^{6}$ and molecular analyses $^{7,8,9}$ have shown that these new mutations arise more commonly on the paternal chromosome. In contrast, unilateral tumours, in which both $R B I$ alleles were mutated only in the somatic retinal cell that became the tumour,

From: Departments of Ophthalmology*, Molecular and Medical Genetics $\dagger$, and Pathology§, University of Toronto, and Division of Immunology and Cancer Researc: 1, rospital for Sick Children, Toronto. *Present address: Division of Biology, California Institute of Technology, 156-29. Pasadena, CA 91125.

Correspondence to: Dr Brenda L. Gallie, Division of Immunology and Cancer Research, The Hospital for Sick Children, 555 University Ave., Toronto, Canada M5G 1 X8. show the initial mutation on either maternal or paternal chromosomes, ruling out somatic imprinting as a mechanism in RB tumours. The paternal germline mutation of $R B 1$ may arise because of the opportunity for mutation in the many cell divisions of spermatogenesis, ${ }^{10}$ or by increased exposure of fathers to mutagens. A case control study has shown a significant association of new germline RB with paternal employment in the military and metal industries. ${ }^{11,12}$ Consistent with accumulation of mutations in sperm, several studies have suggested a small paternal age effect in bilateral but not unilateral RB. ${ }^{13.14,15}$

\section{Types of RBI mutations}

The $R B I$ gene was localised to chromosome 13 by the observation of a constitutional deletion of chromosome 13 in $3 \%$ to $5 \%$ of RB patients. ${ }^{16,17,18,19}$ These children have many abnormalities in addition to RB, for example, cardiac abnormalities, mental retardation, extra digits and a characteristic facial appearance, ${ }^{20}$ depending on the size and extent of the chromosome 13 deletion.

However, most patients with germline mutations affecting only $R B I$ are of normal intelligence and are otherwise normal in every way except for tumour formation. The smallest deletion was specifically localised to band $13 \mathrm{q} 14$ (13q14.1-13q14.3). ${ }^{21}$ The gene was designated ' $R B I$ ' to leave room for another, unmapped, gene ' $R B 2$ ' in which mutations could also lead to RB tumours. It is now likely that all RB tumours are caused by $R B I$ mutations.

Chromosomal localisation of $R B I$ was refined by family studies linking a chromosome $13 \mathrm{q} 14$ marker (esterase $\mathrm{D})$ to the occurrence of $\mathrm{RB} .^{22,23.24}$ The first molecular clone of $R B I$ was obtained by identifying that a unique 13q14 DNA fragment was homozygously deleted in a few RB tumours. ' This genomic DNA fragment was then used to obtain the cDNA of the $R B I$ gene. ${ }^{2} R B I$ spans approximately $200 \mathrm{~kb}$ and contains 27 exons. $^{25}$

Many $R B 1$ mutations in RB tumours and other cancers have been characterised, ${ }^{3,4,5,26,27,28}$ but a complete survey that might indicate 'hot spots' for mutation has not yet been reported. The mutations have been detected by various technologies. ${ }^{3,4,5}$ Currently, the most efficient method 
to find unknown mutations appears to be screening for variations from normal by single-stranded conformation polymorphism ${ }^{29.30}$ of the PCR-amplified exons. The types of mutations leading to RB tumours include deletions, duplications, and point mutations (See figure 1).

As long as one normal $R B I$ allele is present, cells are normal. Although it has been shown in RB tumour cells that both alleles of $R B I$ are expressed ${ }^{4}$ and contribute to the total cellular $\mathrm{p} 110,{ }^{R B I}$ only one functional allele is required. The patient with one mutant $R B I$ allele in every retinal cell has normal retinal development, but is highly predisposed to develop RB tumours.

\section{Loss of the remaining normal chromosome 13 commonly initiates $R B$}

The malignancy is initiated when the only remaining normal $R B I$ allele is lost, leaving the developing retinal cell with no normal $R B I$ gene (See figure 1). In more than $70 \%$ of RB tumours this involves chromosomal events resulting in loss of all or most of the normal chromosome 13. This process was demonstrated initially by esterase $D$ studies, ${ }^{31}$ elaborated by restriction fragment length polymorphism (RFLP) analysis ${ }^{32,33,34}$ and finally was confirmed by $R B I$ mutation identification. ${ }^{3,4,5,26,27}$ In the tumours, the mutant and normal chromosomes recombine to duplicate the region around the mutant $R B I$ allele, while the normal allele is $\operatorname{lost}^{35}$ by loss of heterozygosity (LOH) (See Figure 1). In 30\% of RB, the second RBI mutation is a separate mutation different from the first ${ }^{4}$. The independent, multifocal RB tumours in a single patient each arise by different second $R B I$ mutations.

The cell of origin of $\mathrm{RB}$, the 'retinoblast' is an embryonic cell of the retina that is uniquely susceptible to malignant transformation by $R B I$ mutations. Morphologically, RB tumour cells resemble developing retinal cells prior to differentiation into multiple retinal cell types, ${ }^{36,37}$ but the basis for the preferential impact of $R B I$ mutation in developing retina is not known. When babies with germline $R B I$ mutations are examined at birth, most already have RB. However, about $30 \%$ with no tumours at birth develop multiple tumours in both retinas in the first year of life. The mean number of separate RB tumours arising in patients with germline $R B 1$ mutation is three to four. ${ }^{38,39}$ After three years of age new RB tumours are rarely observed ${ }^{40}$ Presumably, within the first few years of life, the normal, fully differentiated, retinal cells cease proliferation, terminally differentiate, and can no longer form RB tumours. These children are at about a 40,000 times risk to develop RB tumours compared to a child with two normal $R B I$ alleles. The process of $\mathrm{LOH}$ is presumably occurring in all tissues at a similar frequency. Non-retinal cells may tolerate loss of $R B I$ without proliferating out of control, or $R B I$ may be lethal to the cells, so that $\mathrm{LOH}$ does not demonstrate any phenotype. However, once malignancy of many other tissues is initiated by other factors, loss of $R B I$ may contribute a relative growth advantage and is frequently observed, particularly in tissue culture cell lines.
The product of $R B 1$ : properties, function and mutant forms

What is the protein that is so critical in retinal development? The product of the $R B I$ gene is a $110 \mathrm{KD}$ protein $\left(\mathrm{p} 110^{R B I}\right)$ that is transported into the nucleus in all tissues and cell types studied. ${ }^{41,42,43,44}$ In resting normal cells $\left(G_{0}\right.$ and early $G_{1}$ of the cell cycle), only hypophosphorylated p1 $10^{R B I}$ is present. ${ }^{45,46,47}$ As cells begin to prepare for, and initiate DNA synthesis (late $G_{1}$ and $S$ phase of the cell cycle) many $\mathrm{p} 110^{R B I}$ serine and threonine amino acids become phosphorylated ${ }^{48,49}$ by the action of a cell-cycle kinase. $^{48}$

Since absence of $\mathrm{p} 110^{R B I}$ leads to $\mathrm{RB}$ and cancer, the normal function of $\mathrm{p} 110^{R B I}$ must promote non-proliferation. Therefore, the hypophosphorylated form that is present in resting cells is presumed to be the active form. This idea is supported by the observation that the proteins of the DNA tumour viruses that are essential for the virus to transform mammalian cells, do so, by binding to several mammalian proteins including hypophosphorylated, p1 $10^{R B / 50,51,52,53,54}$ presumably preventing the cells from remaining in a resting state.

$\mathrm{p} 110^{R B I}$ functions by interacting with other cellular proteins ${ }^{55,56}$ to influence the activity of other genes. For example, activity of proliferation-promoting genes such as c-fos, ${ }^{57} c-m y c,{ }^{58}$ and $R B I$ itself, is influenced by p1 $10{ }^{R B I}$ The effect of $\mathrm{p} 110^{R B I}$ on other genes may be determined by tissue and development-specific protein complexes that act on specific target DNA sequences ${ }^{59,60,61,62}$ in the regulatory regions of the genes whose activity is modified.

Initial reports indicated that replacement of functional p1 $10^{R B I}$ into tumour cells had a dramatic effect on growth and tumour formation in immune-deficient animals. ${ }^{63,64,65}$ We have observed different results: there is no change in the growth rate or ability to form tumours of RB or breast cancer cells reconstituted with $R B 1$. These reconstituted cells produce $110^{R B I}$ that shows normal features: the correct size, cell cycle-regulated hyperphosphorylation, and binding to the adenovirus transforming protein, Ela. ${ }^{66}$ The ability of the cells to grow in adverse conditions and regulation of growth-promoting genes may be altered. All the cell lines tested have the secondary growth promoting mutations in other genes, that are not overridden by p1 $10,{ }^{R B I}$ suggesting that $R B l$ is a weak tumour suppressor gene. This would be consistent with the restricted cell types in which $R B I$ mutations can initiate cancer. Careful examination of the previously published experiments reveals that the data also supports only a weak tumour suppressor activity for $\mathrm{p} 110 .^{\mathrm{RBI}}$

Most of the $R B I$ mutations found to lead to RB cause a truncated, unstable, protein ${ }^{4}$ (P. Hamel, personal communication), and no p1 $10^{\mathrm{RB} 1}$ is detected in RB tumours. ${ }^{67}$ A minority of $R B 1$ mutations in RB tumours may produce a near-normal protein, ${ }^{4,5}$ but no such cells have been available for study of the protein. In other types of tumours where $R B 1$ mutations contribute to progression of malignancy, stable truncated $\mathrm{p} 110^{\mathrm{RB} 1}$ proteins have been observed. ${ }^{67}$ 


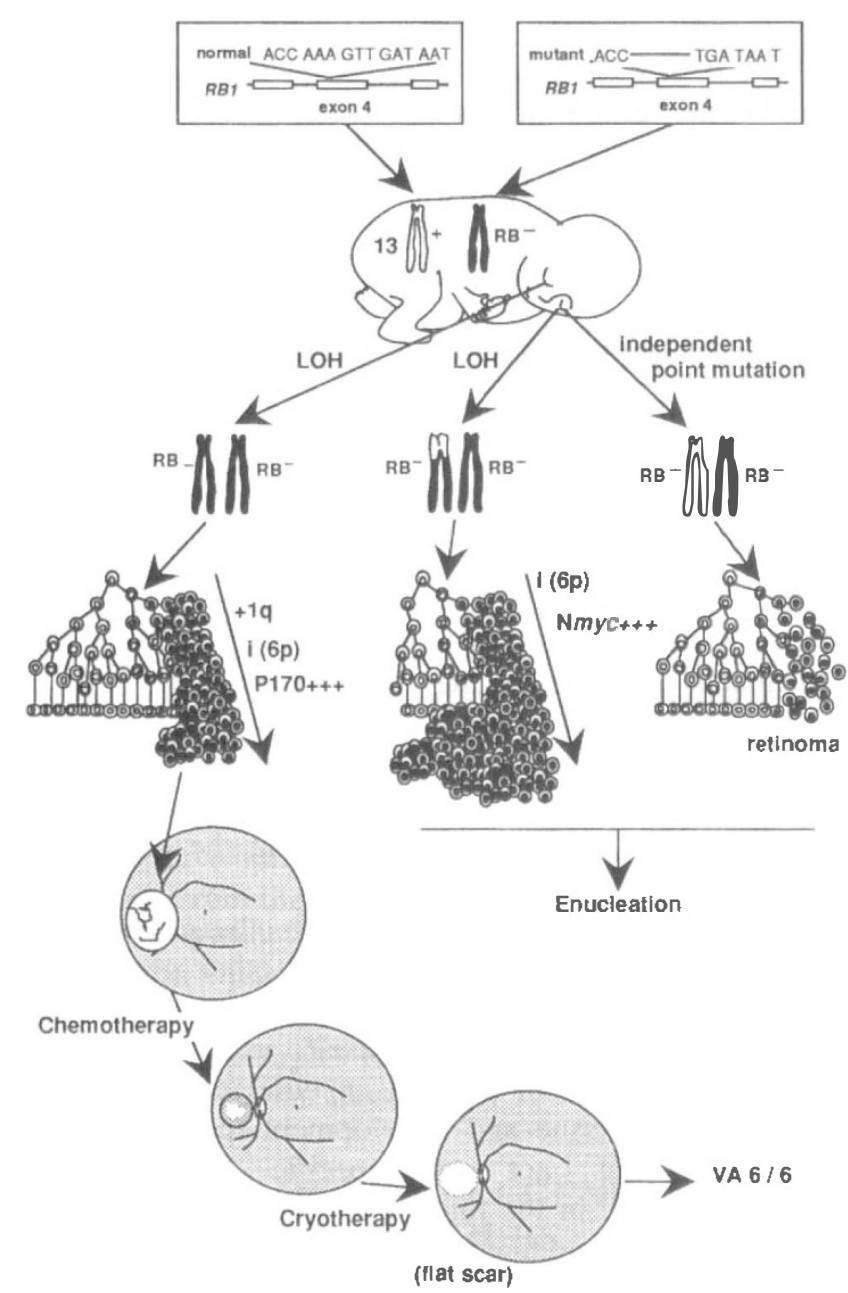

Fig. 1. The figure illustrates a representative case of $R B$, illustrating 'How do Retinoblastoma tumours form?' The paternal RBl allele inherited by the baby suffered a $5 b p$ deletion of exon 4. In late pregnancy, loss of heterozygosity $(\mathrm{LOH})$ occurred in individual retinal cells in each eye, prior to full retinal differentiation. In the left eye, another cell suffered a point mutation of the maternal normal allele. Absence of $P 110^{\mathrm{RB} 1}$ resulted in unregulated proliferation of the cells. An $i(6 p)$ chromosome arose in two of the RB1-clones; $N$-myc oncogene amplification occurred in one, while duplication of Iq occurred in the other. The third RB1-clone proliferated only through several cell divisions without other mutations arising, and reached a non-functional but terminal differentiation. Since further cell divisions could not occur, the abnormality formed only a retinoma. In response to the abnormal retina and absense of photoreceptors, underlying pigment epithelial cells also became abnormal.

The tumour in the left eye proliferated to fill the vitreous cavity, showing to the parents a white pupillary reflex, and leading to diagnosis of $R B$. The tumour in the right eye was of moderate size, overhanging the optic nerve at diagnosis. Although conventional treatment was radiotherapy, a trial of experimental chemotherapy with VM26, vincristine, and high dose cyclosporin A was initiated. The tumour shrank to show its origin nasal to the optic nerve. After six treatments at 10 day intervals, the residual mass was translucent, partially calcified, and about $1 / 3$ the original size. The residual was treated on three occasions with cryotherapy through a conjunctival incision, freezing up to the nasal rim of the optic nerve. No further tumour grow occurred. Ultimate visual acuity was normal, and radiation therapy was avoided.

\section{Clinical application of RBI mutation identification}

Efficient methods are now required to identify the $R B I$ mutation of each family in order to provide accurate genetic counselling. The research technology used so far to identify mutations $s^{3.4,5}$ has been time consuming, costly and not readily available. Now several labs are identifying mutations in RB families ${ }^{30}$ (J. Cowell and B. Gallie, personal communication) by somewhat more efficient methods. The DNA of each exon, amplified by polymerase chain reaction (PCR), is screened by searching for mobility differences of single DNA strands caused by the mutations. ${ }^{29}$ Suspect regions of DNA are sequenced to define the mutation.

Once the mutation is known in a family, screening of relatives is relatively simple and cost effective. The DNA is amplified by PCR with oligonucleotides spanning the mutation. Deletions and duplications are detectable on simple agarose gel electrophoresis by the size of the fragment or by formation of a heteroduplex between mutant and wild type strands, which alters mobility ${ }^{68}$ some point mutations alter restriction enzyme recognition sites; and some may be best detected by specific oligonucleotide probes. Since the alternative to molecular detection of the $R B I$ mutation is the more expensive repeated examinations of infant relatives under anaesthetic for the first three years of life, health care finance must be redirected to molecular mutation identification.

Once a family's $R B I$ mutation is identified, prenatal diagnosis can be offered. Since early diagnosed RB is rarely fatal, ${ }^{69}$ and in most cases blindness can be prevented, few parents will select termination of pregnancy if the fetus is shown to have the mutation. However, diagnosis of the mutation at 36 weeks gestation has been suggested as justification for premature delivery, in order to treat RB earlier, saving more sight and reducing the morbidity of therapy. Ultimately, such individuals will increase the fraction of RB cases that are inherited, if they continue to reproduce.

\section{ADDITIONAL MUTATIONS ARE RQUIRED FOR MALIGNANCY}

Retinoma: too few mutations?

Even if $\mathrm{LOH}$ has resulted in absence of any normal $R B I$ allele or $\mathrm{p} 110^{\mathrm{RB} 1}$ in a developing retinal cell, malignancy may still not result (See Figure 1). Retinoma, the benign equivalent of an RB tumour, appears as a non-proliferating lesion resembling irradiated, inactive tumour, in the untreated retina of individuals with germline $R B I$ mutations. $^{70.71}$ A retinoma that occurs in the same eye as RB tumour can not be clinically recognised, but may be manifest by the residual translucent mass persisting after radiation treatment. ${ }^{72}$

Several explanations may account for retinoma. If both $\mathrm{RB}$ alleles are mutated in a retinoblast that is almost terminally differentiated, limited proliferation may be insufficient for progressive accumulation of the other mutations required for malignancy. RB tumours removed from 
patients show abnormalities in other chromosomes besides chromosome $13:^{73}$ a unique rearrangement of chromosome $6, \mathrm{i}(6 \mathrm{p}) ;^{74,75}$ trisomy of $1 \mathrm{q}$, common in many human solid malignant tumours; ${ }^{76,77}$ occasional DNA amplification of the $\mathrm{N}-m y c$ proto-oncogene, ${ }^{78,79,80}$ a protein expressed normally in retinoblasts, $;^{81,82}$ and overexpression of the membrane transport protein, P170 (See below). Retinomas have not been studied for these progressive genetic mutations since there is no clinical need to remove the eyes, and few specimens are available.

Alternately, retinomas may be determined by the $R B I$ mutations. The germline mutation of a patient with retinoma is not yet described, but two families have been identified that showed fewer than expected RB tumours and had germline mutations in the regulatory region of $R B 1 .^{30}$ It was proposed that such regulatory mutations might result in a small amount of normal p $110^{\mathrm{RB} 1}$, that would account for fewer than the usual number of tumours. Similar mutations could lead to retinoma.

When retinoma is documented in an individual, repeated clinical observations must be carried out to ensure that a cell within the retinoma does not further mutate to become proliferative, malignant $\mathrm{RB} .^{83}$

\section{Resistance to Chemotherapy: too many mutations?}

The majority of cases treated by removal of the eye are cured of cancer, ${ }^{84}$ and the mortality from RB in countries with modern medicine is only $8 \%{ }^{85}$ However, if curative therapy is delayed, the RB tumour may grow into the optic nerve and enter the meningeal space to disseminate throughout the brain and spinal cord. Up to the present time, RB disseminated in the central nervous system has not been curable. Rarely, bone marrow metastases arise without brain involvement, and may be curable by intensive treatment. ${ }^{86}$

Many RB are controlled by radiotherapy, as long as less than half the ocular volume is involved, and no vitreous seeding has occurred. ${ }^{87}$ However, patients with germline $R B 1$ mutations have a several hundredfold risk of developing second primary neoplasms, including osteosarcoma, fibrosarcoma, soft tissue sarcoma, melanoma, brain tumour and others, and this risk is significantly increased by radiotherapy. ${ }^{88.89 .90 .91}$ Therefore, unless radiotherapy is the only way to achieve useful vision, control of the cancer by other therapies such as photocoagulation and cryotherapy is preferable.

Intraocular RB tumours have not been extensively treated by chemotherapy. The drugs available had high toxicity, and systemic potential to also cause second malignancies. ${ }^{90}$ Now, however, we have shown good initial responses of intraocular RB tumours to relatively non-toxic, non-alkylating drugs, VM26 and vincristine. Moderate sized tumours can be shrunk to a size treatable by cryo- or phototherapy. If the tumours remain too large for these treatments however, they become resistant to the effects of the drugs.

The membrane glycoprotein, P170, prevents accumulation of multiple classes of chemotherapeutic agents in cancer cells, and results in multidrug-resistance (MDR) of the tumour cells. ${ }^{92}$ Increased P170 expression in RB tumours correlates well with an MDR phenotype, both in vitro and in vivo. ${ }^{93}$ Several approaches are being developed to specifically counteract P170 and increase the effectiveness of chemotherapy.

Competition for the P170 drug efflux pump, for example by high levels of drugs such as cyclosporin $\mathrm{A},{ }^{94}$ interference with P170 by blockers such as verapamil, ${ }^{95}$ or inactivation of P170 by specific agents such as monoclonal antibodies, ${ }^{92}$ have potential to improve therapy and cure rates for many cancers, including RB. By understanding 'How RB tumours form', we may be able significantly improve prospects for children with RB.

Key words: Retinoblastoma, Molecular genetics, Multidrug resistance, Mutations, Retinoma.

\section{REFERENCES}

1. Dryja TP, Rapaport JM, Joyce JM, Petersen RA: Molecular detection of deletions involving band q14 of chromosome 13 in retinoblastomas. Proc Natl Acad Sci USA 1986, 83(19): 7391-4.

2. Friend SH, Bernards R, Rogelj S, et al.: A human DNA segment with properties of the gene that predisposes to retinoblastoma and osteosarcoma. Nature 1986, 323 (6089): 643-6.

3. Dunn JM, Phillips RA, Becker AJ, Gallie BL: Identification of germline and somatic mutations affecting the retinoblastoma gene. Science 1988, 241(4874): 1797-800.

4. Dunn JM, Phillips RA, Zhu X, Becker AJ, Gallie BL: Mutations in the RB 1 gene and their effects on transcription. Mol. Cell. Biol. 1989, 9: 4594-602.

5. Yandell DW, Campbell TA, Dayton SH, et al.: Oncogenic point mutations in the human retinoblastoma gene: their application to genetic counseling. New Engl J Med 1989, 321(25): 1689-94.

6. Ejima Y, Sasaki MS, Kaneko A, Tanooka H: Types, rates origin and expressivity of chromosome mutations involving $13 \mathrm{q} 14$ in retinoblastoma patients. Hum Genet 1988, 79(2): 118-23.

7. Dryja TP, Mukai S, Petersen R, Rapaport JM, Walton D, Yandell DW: Parental origin of mutations of the retinoblastoma gene. Nature 1989, 339: 556-8.

8. Zhu X, Dunn JM, Goddard AD, et al.: Preferential germline mutation of the paternal allele in retinoblastoma. Nature 1989, 340: 312-13.

9. Leach RJ, Magewu AN, Buckley JD, et al.: Preferential retention of paternal alleles in human retinoblastoma: evidence for genomic imprinting. Cell Growth Differ 1990, 1(9): 401-6.

10. Vogel F, and Rathenberg R: Spontaneous mutation in man. Adv Hum Genet 1985, 5: 223-318.

11. Bunin GR, Meadows AT, Emanuel BS, Buckley JD, Woods WG, Hammond GD: Pre- and postconception factors associated with sporadic heritable and nonheritable retinoblastoma. Cancer Res 1989, 49(20): 5730-5.

12. Bunin GR, Petrakova A, Meadows AT, et al.: Occupations of parents of children with retinoblastoma: a report from the Children's Cancer Study Group. Cancer Res 1990, 50(22): 7129-33.

13. Pellie C, Briard ML, Feingold J, Frezal J: Parental age in retinoblastoma. Humangenetik 1973, 20(1): 59-62.

14. Matsunaga E: Hereditary retinoblastoma: lack of maternal effect. Hum Genet 1982, 62(2): 124-8.

15. DerKinderen DJ, Koten JW, Tan KE, Beemer FA, Van RLK, Den OW: Parental age in sporadic hereditary retinoblastoma. Am J Ophthalmol 1990, 110(6): 605-9. 
16. Orye E, Delbeke MJ, Vandenabeele B: Retinoblastoma and D-chromosome deletions. Lancet 1971, 2(738): 1376.

17. Francke U, Kung F: Sporadic bilateral retinoblastoma and 13q-chromosomal deletion. Med Pediatr Oncol 1976, 2(4): 379-85.

18. Strong LC, Riccardi VM, Ferrell RE, Sparkes RS: Familial retinoblastoma and chromosome 13 deletion transmitted via an insertional translocation. Science 1981, 213(4515): 1501-3.

19. Horsthemke B, Barnert HJ, Greger V, Passarge E, Höpping $\mathrm{W}$ : Early diagnosis in hereditary retinoblastoma by detection of molecular deletions at gene locus. Lancet 1987, 1(8531): 511-2.

20. Motegi T, Kaga M, Yanagawa Y, et al. A recognizable pattern of the midface of retinoblastoma patients with interstitial delection of 13q. Hum Genet 1983, 64(2): 160-2.

21. Yunis JJ, Ramsay N: Retinoblastoma and subband deletion of chromosome 13. Am J Dis Child 1978, 132(2): 161-3.

22. Sparkes RS, Sparkes MC, Wilson MG, et al.: Regional assignment of genes for human esterase $\mathrm{D}$ and retinoblastoma to chromosome band 13q14. Science 1980, 208 (4447): 1042-4.

23. Sparkes RS, Sparkes MC: Esterase D studies in human retinoblastoma. Isozymes Curr Top Biol Med Res 1983, 11: 173-82.

24. Connolly MJ, Payne R H, Johnson G, et al.: Familial, EsDlinked, retinoblastoma with reduced penetrance and variable expressivity. Hum Genet 1983, 65: 122-4.

25. McGee TL, Yandell DW, Dryja TP: Structure and partial genomic sequence of the human retinoblastoma susceptibility gene. Gene 1989, 80: 119-28.

26. Canning S, and Dryja TP: Short, direct repeats at the breakpoints of deletions of the retinoblastoma gene. Proc Natl Acad Sci USA 1989, 86: 5044-48.

27. Lee EY, Bookstein R, Young LJ, Lin CJ, Rosenfeld MG, Lee WH: Molecular mechanism of retinoblastoma gene inactivation in retinoblastoma cell line Y79. Proc. Natl. Acad. Sci. USA 1988, 85(16): 6017-21.

28. Mitchell CD, and Cowell JK: Predisposition to retinoblastoma due to a translocation within the $4.7 \mathrm{R}$ locus. Oncogene $1989,4(2): 253-7$

29. Orita M, Iwahana H, Kanazawa H, Hayashi K, Sekiya T: Detection of polymorphisms of human DNA by gel electrophoresis as single-strand conformation polymorphisms. Proc. Nat'l. Acad. Sci. 1989, 86: 2766-70.

30. Sakai T, Ohtani N, McGee TL, Robbins PD, Dryja TP: Oncogenic germ-line mutations in Sp1 and ATF sites in the human retinoblastoma gene. Nature 1991, 353: 83-6.

31. Godbout R, Dryja TP, Squire J, Gallie BL, Phillips RA: Somatic inactivation of genes on chromosome 13 is a common event in retinoblastoma. Nature 1983, 304(5925): 451-3.

32. Cavenee WK, Dryja TP, Phillips RA, et al.: Expression of recessive alleles by chromosomal mechanisms in retinoblastoma. Nature 1983, 305(5937): 779-84.

33. Dryja TP, Cavenee W, White R, et al.: Homozygosity of chromosome 13 in retinoblastoma. $N$ Engl J Med 1984, 310 (9): 550-3.

34. Cavenee WK: Recessive mutant genes predisposing to human cancer. Prog Clin Biol Res 1986, 209A: 575-82.

35. Zhu X, Dunn JM, Goddard AD, et al.: Mechanisms of Loss of Heterozygosity in Retinoblastoma. Cytogenet and Cell Genet (In press).

36. Popoff NA, and Ellsworth RM: The fine structure of retinoblastoma. In vivo and in vitro observations. Lab Invest 1971, 25(5): 389-402.

37. Popoff N, and Ellsworth RM: The fine structure of nuclear alterations in retinoblastoma and in the developing human retina: in vivo and in vitro observations. J Ultrastructure Res 1969, 29: 535-49.
38. Knudson AGJ: Mutation and cancer: statistical study of retinoblastoma. Proc Natl Acad Sci USA 1971, 68(4): 820-3.

39. Knudson AGJ, Hethcote HW, Brown BW: Mutation and childhood cancer: a probabilistic model for the incidence of retinoblastoma. Proc Natl Acad Sci USA 1975, 72(12): 5116-20.

40. Shields CL, Shields JA, Shah P: Retinoblastoma in older children. Ophthalmology 1991, 98(3): 395-9.

41. Lee WH, Shew JY, Hong FD, et al.: The retinoblastoma susceptibility gene encodes a nuclear phosphoprotein associated with DNA binding activity. Nature 1987, 329(6140): 642-5.

42. Buchkovich K, Duffy LA, Harlow E: The retinoblastoma protein is phosphorylated during specific phases of the cell cycle. Cell 1989, 58(6): 1097-105.

43. Chen PL, Scully P, Shew JY, Wang JY, Lee WH: Phosphorylation of the retinoblastoma gene product is modulated during the cell cycle and cellular differentation. Cell 1989, 58(6): 1193-98.

44. Mihara K, Cao XR, Yen A, et al.: Cell cycle-dependent regulation of phosphorylation of the human retinoblastoma gene product. Science 1989, 246(4935): 1300-3.

45. Ludlow JW, Shon J, Pipas JM, Livingston DM, De Caprio JA: The retinoblastoma susceptibility gene product undergoes cell cycle-dependent dephosphorylation and binding to and release from SV40 large T. Cell 1990, 60(3): 387-96.

46. Furukawa Y, DeCaprio JA, Freedman A, et al.: Expression and state of phosphorylation of the retinoblastoma susceptibility gene product in cycling and noncycling human hematopoietic cells. Proc Natl Acad Sci USA 1990, 87(7): 2770-4.

47. Thomas NS, Burke LC, Bybee A, Linch DC: The phosphorylation state of the retinoblastoma (RB) protein in $\mathrm{G} 0 / \mathrm{G} 1$ is dependent on growth status. Oncogene 1991, 6(2): 317-22.

48. Lin BT, Gruenwald S, Morla AO, Lee WH, Wang JY: Retinoblastoma cancer suppressor gene product is a substrate of the cell cycle regulator cdc2 kinase. Embo J 1991, 10(4): 857-64.

49. Hamel PA, Cohen BL, Sorce LM, Gallie BL, Phillips RA: Hyperphosphorylation of the Retinoblastoma Gene Product is Determined by Domains Outside the SV40 large-T-Binding Regions. Mol. Cell. Biol. 1990, 10: 6586-95.

50. Whyte P, Buchkovich KJ, Horowitz JM, et al.: Association between an oncogene and an anti-oncogene: the adenovirus E1A proteins bind to the retinoblastoma gene product. Nature 1988, 334(6178): 124-9.

51. DeCaprio JA, Ludlow JW, Figge J, et al:: SV40 large tumour antigen forms a specific complex with the product of the retinoblastoma susceptibility gene. Cell 1988, 54(2): 275-83.

52. Dyson N, Howley PM, Münger K, Harlow E: The human papilloma virus-16 E7 oncoprotein is able to bind to the retinoblastoma gene product. Science 1989, 242: 934-7.

53. Kaelin WGJ, Ewen ME, Livingston DM: Definition of the minimal simian virus 40 large $T$ antigen- and adenovirus E1A-binding domain in retinoblastoma gene product. $\mathrm{Mol}$ Cell Biol 1990, 10(7): 3761-9.

54. Ludlow JW, DeCaprio JA, Huang C-M, Lee W-H, Paucha E, Livingston DM: SV40 large T antigen binds preferentially to an underphosphorylated member of the retinoblastoma susceptibility gene product family. Cell 1989, 56: $57-65$.

55. Kaelin WGJ, Pallas DC, De Caprio JA, Kaye FJ, Livingston DM: Identification of cellular proteins that can interact specifically with the T/E1A-binding region of the retinoblastoma gene product. Cell 1991, 64(3): 521-32.

56. Huang S, Lee W-H, Lee EY-HP: A cellular protein that competes with SV40T antigen for binding to the retinoblastoma gene product. 1991, 350: 160-62. 
57. Robbins PD, Horowitz JM, Mulligan RC: Negative regulation of human c-fos expression by the retinoblastoma gene product Nature 1990, 346: 668-71.

58. Hamel PA, Gill RM, Phillips RA, Gallie BL: Transcriptional repression of the E2-containing promoters EIIaE, c- $m y c$ and $R B l$ by the product of the $R B l$ gene. (submitted).

59. Bandara LR, La Thangue NB: Adenovirus Ela prevents the retinoblastoma gene product from complexing with a cellular transcription factor. Nature 1991, 351: 494-7.

60. Chellappan SP, Hiebert S, Mudryl M, Horowitz JM, Nevins JR: The E2F transcription factor is a cellular target for the RB protein. Cell 1991, 65: 1053-61.

61. Bagchi S, Weinmann R, Raychaudhuri P: The retinoblastoma protein copurifies with E2F-I, a E1 A-regulated inhibitor of the transcription factor E2F. Cell 1991, 65: 1063-72.

62. Chittenden T, Livingston DM, Kaelin WG: The T/E1Abinding domain of the retinoblastoma product can interact selectively with a sequence-specific DNA-binding protein. Cell 1991, 65: 1073-82.

63. Huang HJ, Yee JK, Shew JY, et al:: Suppression of the neoplastic phenotype by replacement of the RB gene in human cancer cells. Science 1988, 242(4885): 1563-6.

64. Bookstein R, Shew J-Y, Chen P-L, Scully P, Lee W-H: Suppression of tumorigenicity of human prostate carcinoma cells by replacing a mutated RB gene. Science 1990, 247: 712-15.

65. Sumegi J, Uzolgyi E, Klein G: Expression of the RB gene under the control of MuLC-LTR suppresses tumorigenicity of WERI-Rb-27 retinoblastoma cells in immunodefective mice. Cell Growth \& Differentiation 1990, 1: 247-50.

66. Muncaster M, Cohen B, Phillips RA, Gallie BL: Failure of $\mathrm{RB} 1$ to reverse the malignant phenotype of human tumors cell lines. (submitted).

67. Horowitz JM, Park SH, Bogenmann E, et al:: Frequent inactivation of the retinoblastoma anti-oncogene is restricted to a subset of human tumor cells. Proc Natl Acad Sci USA 1990, 87(7): 2775-9.

68. Gallie BL, Dunn JM, Chan HS, Hamel PA, Phillips RA: The genetics of retinoblastoma. Relevance to the patient. Pediatr Clin North Am 1991, 38(2): 299-315.

69. Plotsky D, Quinn G, Eagle R, Shields J, Granowetter L: Congenital retinoblastoma: A case report. J. Ped. Ophthalmol. \& Strab. 1987, 24: 120-3.

70. Gallie BL, Ellsworth RM, Abramson DH, Phillips RA: Retinoma: spontaneous regression of retinoblastoma or benign manifestation of the mutation? BrJ Cancer 1982, 45(4): 513-21.

71. Gallie BL, Phillips RA, Ellsworth RM, Abramson DH: Significance of retinoma and phthisis bulbi for retinoblastoma. Ophthalmology 1982, 89(12): 1393-9.

72. Abramson DH: Retinoma, retinocytoma, and the retinoblastoma gene [editorial]. Arch Ophthalmol 1983, 101(10): 1517-8.

73. Squire J, Gallie BL, Phillips RA: A detailed analysis of chromosomal changes in heritable and non-heritable retinoblastoma. Hum Genet 1985, 70(4): 291-301.

74. Kusnetsova LE, Prigogina EL, Pogosianz HE, Belkina BM: Similar chromosomal abnormalities in several retinoblastomas. Hum Genet 1982, 61(3): 201-4.

75. Squire J, Phillips RA, Boyce S, Godbout R, Rogers B, Gallie BL: Isochromosome $6 \mathrm{p}$, a unique chromosomal abnormality in retinoblastoma: verification by standard staining techniques, new densitometric methods, and somatic cell hybridization. Hum Genet 1984, 66(1): 46-53.

76. Kovacs G: Abnormalities of chromosome No. 1 in human solid malignant tumors. Int. J. Cancer 1978, 21: 688-94.
77. Brito-Babapulle V and Atkin NB: Break points in chromosome \#1 abnormalities of 218 human neoplasms. Cancer Genet. Cytogenet. 1981, 4: 215-25.

78. Sakai K, Tanooka H, Sasaki MS, Ejima Y, Kaneko A: Increase in copy number of $\mathrm{N}$-myc in retinoblastomas in comparison with chromosome abnormality. Cancer Genet Cytogenet 1988, 30(1): 119-26.

79. Lee WH, Murphree AL, Benedict WF: Expression and amplification of the $\mathrm{N}$-myc gene in primary retinoblastoma. Nature 1984, 309(5967): 458-60.

80. Wakabayashi K, Atsumi S, Sasabe T, Mori S: Low-amplified $\mathrm{N}$-myc gene and pp60src in retinoblastoma TOTL-1 cells which undergo neuron-like differentiation. Cell Struct Funct 1989, 14(3): 331-43.

81. Squire J, Goddard AD, Canton M, Becker A, Phillips RA, Gallie BL: Tumour induction by the retinoblastoma mutation is independent of $\mathrm{N}$-myc expression. Nature 1986, 322 (6079): 55-7.

82. Yokoyama T, Tsukahara T, Nakagawa C, Kikuchi T, Minoda $\mathrm{K}$, Shimatake $\mathrm{H}$ : The $\mathrm{N}$-myc gene product in primary retinoblastomas. Cancer 1989, 63(11): 2134-8.

83. Eagle RCJ, Shields JA, Donoso L, Milner RS: Malignant transformation of spontaneously regressed retinoblastoma, retinoma/retinocytoma variant. Ophthalmology 1989, 96(9): 1389-95.

84. Messmer EP, Heinrich T, Hopping W, de SE, Havers W, Sauerwein W: Risk factors for metastases in patients with retinoblastoma. Ophthalmology 1991, 98(2): 136-41.

85. de Sutter E, Havers W, Hopping W, Zeller G, Alberti W: The prognosis of retinoblastoma in terms of survival. A computer assisted study. Part II. Ophthalmic Paediatr Genet 1987, 8(2): 85-8.

86. Petersen RA, Friend SH, Albert DM: Prolonged survival of a child with metastatic retinoblastoma. J Ped Ophthalmol Strabismus 1987, 24: 247-8.

87. Reese AB, and Ellsworth RM: The evaluation and current concept of retinoblastoma therapy. Trans Am Acad Ophthalmol-Otolaryngol 1963, Mar-Apr:164-172.

88. Abramson DH, Ellsworth RM, Kitchin FD, Tung G: Second nonocular tumors in retinoblastoma survivors: Are they radiation-induced? Ophthalmol 1984, 91: 1351-5.

89. DerKinderen DJ, Koten JW, Nagelkerke NJ, Tan KE, Beemer FA, Den OW: Nonocular cancer in patients with hereditary retinoblastoma and their relatives. Int. J Cancer 1988, 41(4): 499-504.

90. Draper GJ, Sanders BM, Kingston JE: Second primary neoplasms in patients with retinoblastoma. Br J Cancer 1986 , 53(5) 661-71.

91. Roarty JD, McLean IW, Zimmerman LE: Incidence of second neoplasms in patients with bilateral retinoblastoma. Ophthalmology 1988, 95(11): 1583-7.

92. Rothenberg M, and Ling V: Multidrug resistance: molecular biology and clinical relevance. J Natl Cancer Inst 1989, 81(12): 907-10.

93. Chan SL, Canton MD, Gallie BL: Chemosensitivity and multidrug resistance to antineoplastic drugs in retinoblastoma cell lines. Anticancer Res. 1989, 9: 469-74.

94. Twentyman PR, Fox NE, White DJ: Cyclosporin A and its analogues as modifiers of adriamycin and vincristine resistance in a multi-drug resistant human lung cancer cell line. Br J Cancer 1987, 56(1): 55-7.

95. Durie BG and Dalton WS: Reversal of drug-resistance in multiple myeloma with verapamil. Br J Haematol 1988, 68(2): $203-6$. 